\title{
Do Adolescents Who Live or Go to School Near Fast-Food Restaurants Eat More Frequently from Fast-Food Restaurants?
}

\section{Citation}

Forsyth, Ann, Melanie Wall, Nicole Larson, Mary Story, and Dianne Neumark-Sztainer. 2012. Do Adolescents Who Live or Go to School Near Fast-Food Restaurants Eat More Frequently from Fast-Food Restaurants? Health \& Place 18, no. 6: 1261-1269.

\section{Published Version}

doi:10.1016/j.healthplace.2012.09.005

\section{Permanent link}

http://nrs.harvard.edu/urn-3:HUL.InstRepos:12638507

\section{Terms of Use}

This article was downloaded from Harvard University's DASH repository, and is made available under the terms and conditions applicable to Other Posted Material, as set forth at http:// nrs.harvard.edu/urn-3:HUL.InstRepos:dash.current.terms-of-use\#LAA

\section{Share Your Story}

The Harvard community has made this article openly available.

Please share how this access benefits you. Submit a story.

\section{Accessibility}




\title{
Do adolescents who live or go to school near fast-food restaurants eat more frequently from fast-food restaurants?
}

\author{
Ann Forsyth ${ }^{\mathrm{a}, *}$, Melanie Wall $^{\mathrm{b}}$, Nicole Larson ${ }^{\mathrm{c}}$, Mary Story $^{\mathrm{c}}$, Dianne Neumark-Sztainer $^{\mathrm{c}}$ \\ a Department of Urban Planning and Design, Harvard University, Cambridge, MA 02138, USA \\ ${ }^{\mathrm{b}}$ Division of Biostatistics, Department of Psychiatry and Department of Biostatistics, Mailman School of Public Health, Columbia University, New York, NY 10032, USA \\ ${ }^{\mathrm{c}}$ Division of Epidemiology and Community Health. School of Public Health, University of Minnesota, Minneapolis, MN 55454, USA
}

\section{A R T I C L E I N F O}

Article history:

Received 9 February 2012

Received in revised form

27 August 2012

Accepted 6 September 2012

Available online 15 September 2012

Keywords:

Fast food

Restaurants

Neighborhood

School

Adolescents

\begin{abstract}
A B S T R A C T
This population-based study examined whether residential or school neighborhood access to fast food restaurants is related to adolescents' eating frequency of fast food. A classroom-based survey of racially/ ethnically diverse adolescents $(n=2724)$ in 20 secondary schools in Minneapolis/St. Paul, Minnesota was used to assess eating frequency at five types of fast food restaurants. Black, Hispanic, and Native American adolescents lived near more fast food restaurants than white and Asian adolescents and also ate at fast food restaurants more often. After controlling for individual-level socio-demographics, adolescent males living near high numbers fast food restaurants ate more frequently from these venues compared to their peers.
\end{abstract}

(c) 2012 Elsevier Ltd. All rights reserved.

\section{Introduction}

Do adolescents who live or go to schools near fast food restaurants eat more frequently from these restaurants? A number of studies have examined whether adolescents who live near or go to schools close to fast food restaurants are more likely to be overweight (Crawford et al., 2008; Oreskovic et al., 2009; Powell et al., 2007a,2007b). Few, however, have investigated whether youth eat more often at fast food restaurants if there are many such restaurants near their home or school (c.f. Laska et al., 2010; An and Sturm, 2012). None have explicitly examined whether those who live near different types of fast food restaurants (e.g. pizza, burgers-and-fries, Mexican) eat more often at these types of fast food restaurants. This paper addresses these gaps in the evidence base.

Studies of neighborhood food environments of adolescents have typically measured dietary intake of foods such as fruits and vegetables, or outcomes such as body mass index (BMI), but not frequency of eating at fast food restaurants (Davis and Carpenter, 2009; Ding et al., in press; Jago et al., 2007; Timperio et al., 2008). A recent review of the relationship between the neighborhood food environment and obesity in children and adolescents

\footnotetext{
* Corresponding author. Tel.: +1 617496 3587; fax: +16174961292.

E-mail addresses: aforsyth@gsd.harvard.edu.edu (A. Forsyth), mmw2177@columbia.edu (M. Wall), larsonn@umn.edu (N. Larson), story@epi.umn.edu (M. Story), neuma011@umn.edu (D. Neumark-Sztainer).
}

concluded that results have been mixed (De Vet et al., 2010). However, there is more consistent evidence that vulnerable populations, such as low-income and African American youth tend to live in areas with a disproportionate share of fast food restaurants (Block et al., 2004; Kwate et al., 2009), and that fast food restaurants may cluster near schools (Austin et al., 2005; Zenk and Powell, 2008; c.f. Seliske et al., 2009). Despite concerns about the high number of fast food restaurants in low-income neighborhoods and the importance of promoting healthy eating behaviors during adolescence (10-19 years) (WHO, 2012), only a few studies have examined how access to fast food restaurants may be related to frequency of eating at fast food restaurants among adolescents.

Laska et al. (2010) examined both home and school neighborhood environments and a range of outcomes, including fast food purchases among 349 adolescents in Minnesota, and found significant associations between sugar-sweetened beverage intake and proximity to a number of different retail and restaurant types including fast food restaurants. Several other outcome variables showed no statistically significant associations with proximity of homes and schools to various types of retail shops and restaurants, including energy intake, dietary fat, fruit and vegetable intake, fast food purchases, and combined fast food and convenience store purchases.

An and Sturm (2102) used the 2005 and 2007 waves of the California Health Interview Survey of children $(N=8226)$ and adolescents $(N=5236)$ that asked about one day of fast food 
consumption. They compared consumption of a variety of foods, including fast food, with numbers of food outlets in circular radii around homes and schools at 0.1, 0.5, 1.0, and 1.5 miles. They found no evidence to support the proposal that better access to supermarkets, or less exposure to fast food restaurants or convenience stores within walking distance, is related to higher diet quality or lower BMI among Californian youth (An and Sturm, 2012: 131).

Most other research that has explored the relationship between neighborhood-level proximity to fast food restaurants and fast food consumption has focused on adults (Moore et al., 2009; Boone-Heinonen et al., 2011; Richardson et al., 2011). Findings are inconsistent with some studies finding no association and others finding that adults are affected by their environment (Fleischhacker et al., 2011). For example, using longitudinal data from the CARDIA study $(n=5115)$, Boone-Heinonen et al. (2011) found some associations between fast food consumption and proximity of restaurants among low-income men but not other groups. Using cross-sectional data on young adults (ages 18-28) enrolled in the National Longitudinal Study of Adolescent Health $(n=13,150)$ Richardson et al. did not find an association between availability of fast food near residences and weekly fast food consumption.

The current study among a racially, ethnically, and socioeconomically diverse sample of adolescents expands on the limited body of research on associations between proximity of fast food restaurants near homes and schools and frequency of eating at fast food restaurants. Specifically, this study addresses three questions: (1) Do adolescents who live or go to school in areas with more fast food restaurants eat more frequently at fast food restaurants? (2) Do associations differ by type of fast food restaurant (e.g., pizza, traditional burger-and-fries)? and (3) Do these patterns differ by gender, ethnicity/race, or socioeconomic status? We hypothesized that adolescents living and going to schools in areas with more fast food restaurants would eat out more at fast food restaurants. We further hypothesized that associations would be attenuated, but would remain statistically significant, after adjusting for socio-demographic characteristics, such as race, ethnicity, and socioeconomic status.

\section{Methods}

\subsection{Sample and study design}

As has been reported elsewhere (Wall et al., 2012) data were drawn from EAT 2010 (Eating and Activity in Teens), a population-based study examining dietary intake, physical activity, weight control behaviors, weight status, and factors associated with these outcomes. The study population included adolescents from 20 public middle schools and high schools in the Minneapolis/St. Paul metropolitan area of Minnesota, which serve socioeconomically and racially/ethnically diverse communities. There were 2724 adolescents who completed classroom surveys during the 2009-2010 academic year. Questions assessed how often they ate away from home at restaurants. Geographic Information Systems (GIS) data were used to assess fast food restaurants near their home and school. Mean participant age was 14.5 years $(\mathrm{SD}=2.0) ; 45.1 \%$ were in middle school (6th-8th grades) and 54.9\% were in high school (9th-12th grades). Participants were equally divided by gender (53.4\% girls). Racial/ethnic backgrounds were: $18.5 \%$ white, $29.3 \%$ African American or black, 20.0\% Asian American, 16.9\% Hispanic, 3.6\% Native American, and $11.5 \%$ mixed or other.

Trained research staff administered surveys during two class periods of 45-50 min each. Following survey completion, participants were given a \$10 Target discount department store gift card. All study procedures were approved by the University of Minnesota's Institutional Review Board and by the participating school districts. Adolescents were given the opportunity to assent only if their parent/ guardian did not return a signed consent form indicating their refusal to have their child participate. Among adolescents who were at school on the days of survey administration, 96.3\% had parental consent and chose to participate.

\subsection{Survey measures}

Frequency of eating from five categories of fast food restaurants (burger-and-fries, fried chicken, Mexican, pizza, and sandwich/ sub restaurants) was assessed with the question: "In the past month, how often did you eat something from the following types of restaurants (include take-out and delivery?" For each of the five categories of fast food restaurants, examples of restaurant chains were provided (e.g., McDonald's, Panera Bread). Response options were never/rarely, 1-3 times per month, 1-2 times per week, 3-4 times per week, 5-6 times per week, and 1+ times per day. Responses were scored to times/week respectively as: $0,0.5$, $1.5,3.5,5.5$, and 7 and were summed across the five fast food restaurant types. The one-week test-retest reliability of reported frequencies among a sample of 129 adolescents during the pilot testing varied according to the type of food served at restaurants, ranging from 0.40 (sandwiches/subs) to 0.59 (fried chicken). The overall test-retest reliability for frequency of eating from fast food restaurants was 0.49 . To prevent outlying values from influencing results, responses were truncated at 21 times per week (i.e., 3 fast food meals per day).

Socio-demographic characteristics were self-reported by adolescent participants, including their gender, age, race/ethnicity, grade level, and measures of socioeconomic status (SES). Ethnicity/race was assessed with the question: "Do you think of yourself as...? (1) white, (2) black or African American, (3) Hispanic or Latino, (4) Asian American, (5) Native Hawaiian or Pacific Islander, (6) American Indian or Native American, or (7) other" (test-retest agreement $=98-100 \%$ ). Since very few adolescents reported "Hawaiian or Pacific Islander", or did not report their ethnicity/race, they were coded as "mixed or other." SES was determined primarily using the higher education level of either parent. To address possible misclassification as high SES of participants facing economic distress, an algorithm was developed that also took into account family eligibility for public assistance, eligibility for free or reduced-cost school meals, and parental employment status (Sherwood et al., 2009; NeumarkSztainer et al., 2002; Wall et al., 2012).

\subsection{School environment assessment}

A school food service professional at each of the 20 schools completed a survey for the 2009-2010 academic year on school food availability and nutrition policies, including whether students were allowed to leave campus during the lunch period. Respondents were encouraged to confer with others at their school if they were unsure of current policies or practices. The question on open campus policies (allowing students to leave campus during lunch) asked separately about each grade at the school. For analysis, open campuses were defined as allowing students in any grade to leave campus at lunch. As open campus policies were reported only by senior high schools that enrolled students in grades 9-12, analyses relating to these policies were restricted to the 8 senior high schools in the study. 


\subsection{Neighborhood environment assessment}

GIS data were used to assess socio-demographic characteristics of residential neighborhoods and access to fast food as well as total restaurants in residential and school neighborhood environments in the Minneapolis/St. Paul metropolitan area. Home and school addresses were geocoded and street network buffers created around them using ArcGIS Version 9.3.1 (ESRI, Redlands, California, 2009). The street network buffers were of a new, consistent format called the "sausage" buffer that buffered $150 \mathrm{~m}$ on either side of each road out the distance of the buffer. Sausage buffers are comparable to other network buffers but easier to replicate across platforms (Forsyth, 2012; Forsyth et al., 2012). For EAT 2010, buffer distances of $800 \mathrm{~m}(\mathrm{~m}), 1600 \mathrm{~m}$, and $3000 \mathrm{~m}$ were selected for examining access to restaurants, based on the results of prior research (Davis and Carpenter, 2009; Laska et al., 2010). To focus on the effect of the nearby neighborhood, this paper's analysis uses the smaller two buffer distances. Measures of distance to the nearest restaurant used the OD Cost Matrix option in the Network Analyst Extension of ArcGIS 9.3.1 (Forsyth, 2012).

U.S. census data (Year 2000 census tract boundaries and 2005-2009 American Community Survey 5-year estimates) were used to determine median household income, percent black, percent Asian, percent non-Hispanic White, and percent Hispanic for each tract of residence (U.S. Census Bureau, 2009). Commercial databases (accessed through ESRI Business Analyst, 2010) were used along with North American Industrial Classification System (NAICS) codes (722110, 722211, 722212, and 722213) to identify restaurants. Business Analyst incorporates data from Infogroup that uses white and yellow pages, annual reports, Securities and Exchange Commission information, government data, business magazines, and U.S. postal service information. Each year InfoGroup verifies by phone the information for each business in the database (Esri, 2011, (1). InfoUSA has been used in other comparable studies (e.g. An and Sturm, 2012). A Minnesota-based comparison of multiple sources of food environment data, including local licensing data, InfoUSA/Business Analyst and its main competitor, Dun and Bradstreet concluded that InfoUSA was cost effective, with good geographic coverage (Forsyth et al., 2010). While consistent food sales licensing data were not available across the metropolitan area, the researchers compared licensing data with Business Analyst in 50 zip codes $(r=0.70)$. In 2009, after the empirical work for that study but before the work for this current paper was conducted, Esri further improved its business listing by better dealing with multiple businesses at the same address, increasing its listings by 5\% (Esri 2011: 1).

To identify fast food restaurants, the research team searched the resulting list of restaurants for chain names (a list of over 60) and 18 keywords such as "take out", "fried", and "pizza" (Forsyth, 2012; Forsyth et al., 2010). Subtypes of fast food restaurants were identified in an iterative process. The research team reviewed the complete list of fast food restaurants and sorted them according to their knowledge of the main menu items, unless the restaurant type was obvious from the restaurant name (i.e., pizza restaurants). If the research staff were unfamiliar with the restaurant, then the restaurant was searched online or (more rarely) the restaurant was called to clarify what general type of food was served. Two research staff separately classified the restaurants and then met to resolve any differences. The main weakness of Business Analyst identified by Forsyth et al. (2010) was in coding businesses by type, but as the study team coded fast food restaurants using names this issue was minimized. Others have pointed out that fieldwork is superior to commercial business databases in assessing the nutrition level of food in food stores (such as convenience and grocery stores) where availability of different food types varies across stores (Kersten et al., 2012). This is also a problem with restaurants, though in the case of fast food restaurants there is presumably more uniformity of food types across facilities.

\subsection{Statistical analysis}

Bivariate analyses examined associations between adolescent reported weekly frequency of fast food restaurant usage and (a) distances to fast food restaurants and (b) counts of fast food restaurants in buffers around homes and schools. The frequency of eating out at fast food restaurants on a weekly basis (both total fast food restaurants and subtypes used most frequently by adolescents) was explored by individual-level and neighborhood socio-demographic variables. Multivariate analyses investigated the relationship between eating at fast food restaurants and restaurant proximity and numbers, for both home and school, adjusting for socio-demographic confounders. Both fast food restaurants in general and specific types of fast food restaurants (burger-and-fries, pizza, sandwich/sub, and other) were analyzed. Additional analyses examined whether adolescents attending senior high schools with open campus lunch policies (5 high schools) ate more fast food than those whose high schools did not permit leaving the campus ( 3 high schools). A multilevel model with a random effect for school and controlling for individuallevel socio-demographic variables was used to test the dichotomous open lunch policy variable related to frequency of individual level fast food intake in the 8 high schools.

Given the numerous associations examined in our analyses it is important to keep in mind the possibility of Type 1 errors arising from multiple testing. Because we consider several separate analyses with different predictors and different outcomes, it is not straightforward to apply a single correction to all of our results for multiple comparisons. While we use $p<0.05$ as a guidance for identifying significant relationships, we always present the $p$-value out to 3 decimal places so other cut-offs could be chosen. All analyses were performed in SAS V9.2.

\section{Results}

\subsection{Neighborhood environments}

Of the 2724 adolescent study participants with GIS data, 91\% lived in Minneapolis or St. Paul and 9\% in nearby suburban municipalities. Students lived a median street distance of $4.3 \mathrm{~km}(\mathrm{~km})$ from the schools located in Minneapolis and St. Paul, and $12.0 \mathrm{~km}$ from the one school located within a suburban area.

Descriptive statistics for distance to the nearest fast food restaurant, as well as the counts of restaurants within different buffers around participants are shown in Table 1 . The median distance of fast food restaurants from participant homes was $795 \mathrm{~m}(\mathrm{~m})$ but only $430 \mathrm{~m}$ from participants' schools. There was a median of 5.0 fast food restaurants within $1600 \mathrm{~m}$ (approximately one mile) of participants' homes and 4.0 within the same distance of their schools; for the $800 \mathrm{~m}$ buffers the median was 1.0 for both homes and schools. Pizza restaurants were the most common subtype of fast food restaurants. Subsequent analyses used a $1600 \mathrm{~m}$ buffer around participant homes but $800 \mathrm{~m}$ around schools, as adolescents would likely have more limited time in the school day to visit fast food restaurants. For measurements not reported in the table, there were on average 21.0 and a median of 15.0 total restaurants (fast food or non-fast food) within 1600 m of participants' homes; thus, fast food restaurants comprised around one-third of all restaurants in the vicinities of adolescents' homes. 
Table 1

Descriptive statistics for food environment near adolescent participant HOMES and SCHOOLS. ${ }^{a}$

\begin{tabular}{|c|c|c|c|c|c|}
\hline Fast food type and geography & Mean & SD & Median & Lower quartile & Upper quartile \\
\hline \multicolumn{6}{|l|}{ Environment around participant HOMES } \\
\hline Distance to nearest fast food restaurant $(\mathrm{m})^{\mathrm{b}}$ & 900 & 596 & 795 & 496 & 1157 \\
\hline \multicolumn{6}{|l|}{$800 \mathrm{~m}$ network buffer count of restaurants } \\
\hline Total fast food restaurants & 1.4 & 2.0 & 1.0 & 0.0 & 2.0 \\
\hline Traditional burgers-and-fries & 0.3 & 0.7 & 0.0 & 0.0 & 0.5 \\
\hline Pizza & 0.5 & 0.8 & 0.0 & 0.0 & 1.0 \\
\hline Subs and sandwiches & 0.2 & 0.6 & 0.0 & 0.0 & 0.0 \\
\hline Other fast food ${ }^{\mathrm{c}}$ & 0.4 & 0.8 & 0.0 & 0.0 & 0.0 \\
\hline \multicolumn{6}{|l|}{$1600 \mathrm{~m}$ network buffer } \\
\hline Total fast food restaurants & 5.7 & 5.2 & 5.0 & 2.0 & 8.0 \\
\hline Traditional burgers-and-fries & 1.4 & 1.4 & 1.0 & 0.0 & 2.0 \\
\hline Pizza & 2.0 & 1.8 & 2.0 & 1.0 & 3.0 \\
\hline Subs and sandwiches & 1.0 & 1.7 & 1.0 & 0.0 & 1.0 \\
\hline Other fast food & 1.3 & 2.0 & 1.0 & 0.0 & 2.0 \\
\hline \multicolumn{6}{|l|}{ Environment around participant SCHOOLS } \\
\hline Distance to nearest fast food restaurant $(\mathrm{m})^{\mathrm{b}}$ & 576 & 367 & 430 & 334 & 848 \\
\hline \multicolumn{6}{|l|}{800 m network buffer } \\
\hline Total fast food restaurants & 1.6 & 1.6 & 1.0 & 0.0 & 3.0 \\
\hline Traditional burgers-and-fries & 0.4 & 0.7 & 0.0 & 0.0 & 1.0 \\
\hline Pizza & 0.6 & 0.7 & 0.5 & 0.0 & 1.0 \\
\hline Subs and sandwiches & 0.3 & 0.5 & 0.0 & 0.0 & 1.0 \\
\hline Other fast food & 0.3 & 0.6 & 0.0 & 0.0 & 0.0 \\
\hline \multicolumn{6}{|l|}{$1600 \mathrm{~m}$ network buffer } \\
\hline Total fast food restaurants & 5.0 & 3.3 & 4.0 & 2.5 & 7.5 \\
\hline Traditional burgers-and-fries & 1.0 & 1.0 & 1.0 & 0.0 & 1.5 \\
\hline Pizza & 2.0 & 1.5 & 2.0 & 1.0 & 2.5 \\
\hline Subs and sandwiches & 0.9 & 0.8 & 1.0 & 0.0 & 1.5 \\
\hline Other fast food & 1.2 & 1.3 & 1.0 & 0.0 & 1.5 \\
\hline
\end{tabular}

a Data are for participants for whom GIS data were available $N=2724$.

${ }^{b}$ All linear measures in meters along the street network.

" For GIS measures "other" fast food mainly included fried chicken and Mexican restaurants but also includes some other types such as cookie shops, fried fish restaurants, and Asian take-outs.

\subsection{Fast food restaurant access and socio-demographics}

The number of fast food restaurants within a $1600 \mathrm{~m}$ network buffer of homes was found to differ according to socio-demographic characteristics of students (Table 2). Unadjusted analyses showed that whites and Asians had 1.2 to 1.7 fewer fast food restaurants near their homes than Hispanic, Native American, and black or African American students. This result is statistically significant $(p<0.05)$ and remained so after mutually adjusting for other individual-level covariates, including gender, SES, and grade level. Similarly, numbers of fast food restaurants differed by grade level and neighborhood median household income, but not gender, in both adjusted and unadjusted analyses. Adolescents with lower individual-level SES were more likely than others to have a higher number of fast food restaurants within $1600 \mathrm{~m}$ of their home. After adjusting for other individual-level sociodemographics, however, this result was of borderline significance $(p=0.053)$.

Fast food restaurant access was also related to neighborhood demographic characteristics. Adolescents living in census tracts with lower than the sample median household income (i.e. $<\$ 41 \mathrm{~K}$ per year) had on average 6.6 fast food restaurants within $1600 \mathrm{~m}$ of their home which was significantly higher $(p$-value $<0.0001)$ compared to neighborhoods with higher incomes (4.8 fast food restaurants.) Differences also existed in the average number of fast food restaurants when comparing neighborhoods with higher than median percent of black residents (i.e. $>15 \%$ black) such that adolescents in those neighborhoods had on average 6.3 fast food restaurants nearby compared to 5.1 in the neighborhood with below median percent black $(p$-value $<0.001)$. The opposite pattern was found for neighborhoods with higher than median percent Asians (i.e. $>8 \%$ Asian) such that those adolescents had access to fewer $(p<0.0001)$ fast food restaurants (5.0) compared to those in neighborhoods with fewer Asians, which had on average 6.4 fast food restaurants.

\subsection{Fast food restaurant eating frequency and socio-demographics}

As can be seen in Table 3, significant differences in the weekly frequency of eating out at fast food restaurants by race/ethnicity and SES were evident, but there were no differences by gender or grade level. Blacks ate at fast food restaurants twice as often on a weekly basis compared with whites or Asians and also tended to eat fast food from each type of fast food restaurant (i.e. traditional "burger and fries", pizza, subs and sandwiches, and others) more frequently than youth from other ethnic/racial groups. Increasing SES was associated with decreasing frequency of eating at a fast food restaurant each week and this pattern held for each type of fast food restaurant.

\subsection{Fast food restaurant eating frequency and access}

Table 4 presents frequency of eating at fast food restaurants for males and females by numbers of fast food restaurants within $1600 \mathrm{~m}$ of participants' homes and $800 \mathrm{~m}$ of participants' schools. We tested for two kinds of associations. First was whether there was a trend for those who lived in neighborhoods with more fast food restaurants to eat at these restaurants more frequently compared to those with fewer fast food restaurants. Second was whether those who lived in residential neighborhoods with the 
Table 2

Number of fast food restaurants within 1600 m network buffer of HOMES by socio-demographic characteristics of adolescents in EAT 2010.

\begin{tabular}{|c|c|c|c|c|}
\hline Characteristic & $\begin{array}{l}N \\
\text { (participants) }\end{array}$ & $\begin{array}{l}\text { Mean (restaurants/ } \\
\text { participant) }\end{array}$ & $\begin{array}{l}\text { Std } \\
\text { Dev }\end{array}$ & $\begin{array}{l}\text { Mean } \\
\left(_{(\text {adj })^{a}}\right.\end{array}$ \\
\hline \multicolumn{5}{|l|}{ Ethnicity/Race ${ }^{\mathrm{b}}$} \\
\hline White & 504 & $4.8 \mathrm{a}^{\mathrm{b}}$ & 4.6 & $4.9 \mathrm{a}$ \\
\hline Black or African American & 796 & $6.2 \mathrm{~b}$ & 6.3 & $6.2 \mathrm{~b}$ \\
\hline Asian & 544 & $5.0 \mathrm{a}, \mathrm{c}$ & 3.6 & $5.0 \mathrm{a}$ \\
\hline Hispanic or Latino & 460 & $6.5 \mathrm{~b}$ & 5.2 & $6.4 \mathrm{~b}$ \\
\hline American Indian or Native American & 97 & $6.3 \mathrm{~b}$ & 4.9 & $6.5 \mathrm{~b}$ \\
\hline Mixed or other & 323 & $5.7 \mathrm{~b}, \mathrm{c}$ & 5.4 & $5.8 \mathrm{~b}$ \\
\hline Test for an overall race effect ( $p$-value) & & $<0.001$ & & $<0.001$ \\
\hline \multicolumn{5}{|l|}{ Gender } \\
\hline Boys & 1268 & 5.8 & 5.1 & 5.8 \\
\hline Girls & 1456 & 5.7 & 5.4 & 5.7 \\
\hline Test for difference between genders ( $p$-value) & & 0.740 & & 0.553 \\
\hline \multicolumn{5}{|l|}{ SES } \\
\hline Low & 1055 & 6.1 & 5.8 & 6.0 \\
\hline Low-middle & 582 & 5.6 & 4.4 & 5.5 \\
\hline Middle & 457 & 5.3 & 5.3 & 5.4 \\
\hline Upper-middle & 337 & 5.3 & 5.3 & 5.5 \\
\hline High & 194 & 5.1 & 4.0 & 5.4 \\
\hline Missing SES & 99 & 6.9 & 4.6 & 7.1 \\
\hline Test for a trend by $S E S^{c}$ & & $<0.001$ & & 0.053 \\
\hline \multicolumn{5}{|l|}{ Grade level } \\
\hline Middle school & 1227 & 5.2 & 4.8 & 5.2 \\
\hline High school & 1497 & 6.1 & 5.5 & 6.1 \\
\hline $\begin{array}{l}\text { Test for difference between middle school and high } \\
\text { school ( } p \text {-value) }\end{array}$ & & $<0.001$ & & $<0.001$ \\
\hline
\end{tabular}

${ }^{a}$ Mutually adjusting for other covariates including gender, individual SES, individual race, and grade level.

b Ethnicities/races with different group letters are statistically significantly different at the $p<0.05$ level.

c Test for trend by SES does not include those with missing SES $(n=99)$.

most fast food restaurants, as defined by having 11 or more fast food restaurants within $1600 \mathrm{~m}$ buffer corresponding to approximately the top $10^{\text {th }}$ percentile of fast food restaurant density in the sample, ate from these places significantly more. Boys (but not girls) from such areas with the highest numbers fast food restaurants ate from fast food restaurants significantly more often than those who had lower numbers of fast food restaurants in their neighborhoods. Boys with 11 or more fast food restaurants within $1600 \mathrm{~m}$ ate on average 4.5 meals per week at fast food restaurants, compared with 3.2-3.6 meals per week for those with 0 to 8 fast food restaurants nearby and 4.0 meals for those with 9-10 restaurants nearby. The result remained significant $(p=0.044)$ after adjusting for individual-level socio-demographics.

There were no significant results for the school neighborhood (Table 4) or open campus policy assessment. The average frequency of total fast food restaurant usage did not differ $(p=0.157)$ between those high school students attending schools with open campus policies (3.7 times/week, standard error $(\mathrm{SE})=0.3$ ) and those at schools not permitting students to leave campus (3.0 times/week, $\mathrm{SE}=0.4$ ).

\subsection{Sub-type of fast food restaurant eating frequency and access}

We also analyzed whether adolescents who lived near or went to school near different types of fast food restaurants reported eating from these restaurants more often than youth who did not live as close. For homes, we analyzed whether there was a trend for those who lived near fast food restaurants of certain types to eat more from these places, as well as whether those youth living near the most restaurants of a subtype (4 or more) frequented these fast food restaurants more. For example, we looked at the association of weekly frequency of eating fast food from traditional "burgers and fries" places with the count of the number of traditional burger and fries restaurants within a $1600 \mathrm{~m}$ buffer. The same was done specifically for pizza, subs and sandwiches and then all other fast food combined. For schools, given the smaller numbers of restaurants within $800 \mathrm{~m}$ buffers and the smaller number of schools, we only analyzed whether those going to school near any (versus none) of the fast food restaurants of a particular type reported eating more frequently that particular type of fast food (see Table 5).

For residential areas, most of the significant results involved frequency of fast food restaurant usage by adolescent males. Males in areas with more pizza and sub/sandwich restaurants ate fast food of those types more frequently even after adjusting for socio-demographics (trend). Males in areas with the greatest numbers of pizza, sub/sandwich, and "other" fast food restaurants also ate at these types of fast food restaurants more often. In analyses not shown in the tables, we found that most of the significance of the trend was due to the large jump in intake in locations with the most fast food restaurants of the particular types (i.e. 4 or more). Adolescent females had higher frequency of eating fast food of type "other" (i.e. Mexican and Fried Chicken) in areas where there were the largest numbers of such restaurants, after adjusting for socio-demographics. For schools there were no significant results.

\section{Discussion}

In answering one of the key questions of this paper, whether adolescents who live or attend schools in neighborhoods with 
Table 3

Subtypes of fast food (FF) eaten by socio-demographic characteristics of adolescents in mean meals per week. ${ }^{a}$

\begin{tabular}{|c|c|c|c|c|c|}
\hline & $\begin{array}{l}\text { Total FF } \\
\text { meals/week }\end{array}$ & $\begin{array}{l}\text { Traditional } \\
\text { "burger and fries" }\end{array}$ & $\begin{array}{l}\text { Subs and } \\
\text { sandwiches }\end{array}$ & Pizza $^{\mathrm{a}}$ & $\begin{array}{l}\text { Other fast } \\
\text { food }^{\text {b }}\end{array}$ \\
\hline $\begin{array}{l}\text { Mean frequency of eating at FF } \\
\text { restaurants per week }\end{array}$ & 3.6 & 0.9 & 0.8 & 0.9 & 1.2 \\
\hline \multicolumn{6}{|l|}{ Ethnicity/Race } \\
\hline White & $2.5^{\mathrm{a}}$ & $0.7^{\mathrm{a}}$ & $0.6^{\mathrm{a}, \mathrm{c}}$ & $0.6^{\mathrm{a}}$ & $0.5^{\mathrm{a}}$ \\
\hline Black or African American & $5.1^{\mathrm{b}}$ & $1.2^{\mathrm{b}}$ & $1.1^{\mathrm{b}}$ & $1.3^{\mathrm{b}}$ & $1.8^{\mathrm{b}}$ \\
\hline Asian & $2.5^{\mathrm{a}}$ & $0.7^{\mathrm{a}}$ & $0.5^{\mathrm{a}}$ & $0.6^{\mathrm{a}}$ & $0.8^{\mathrm{a}, \mathrm{c}}$ \\
\hline Hispanic or Latino & $3.3^{\mathrm{c}}$ & $0.8^{\mathrm{a}}$ & $0.7^{\mathrm{c}, \mathrm{d}}$ & $0.7^{\mathrm{a}, \mathrm{c}}$ & $1.2^{\mathrm{d}, \mathrm{e}}$ \\
\hline American Indian or Native American & $3.6^{c, d}$ & $0.9^{\mathrm{a}, \mathrm{c}}$ & $0.9^{b, d}$ & $0.9^{\mathrm{c}, \mathrm{d}}$ & $1.0^{\mathrm{c}, \mathrm{e}}$ \\
\hline Mixed or other & $4.2^{\mathrm{d}}$ & $1.1^{\mathrm{b}, \mathrm{c}}$ & $0.9^{\mathrm{d}}$ & $1.0^{\mathrm{d}}$ & $1.4^{\mathrm{d}}$ \\
\hline $\begin{array}{l}\text { Test for an overall race effect } \\
(p \text {-value })\end{array}$ & $<\mathbf{0 . 0 0 1}$ & $<\mathbf{0 . 0 0 1}$ & $<\mathbf{0 . 0 0 1}$ & $<\mathbf{0 . 0 0 1}$ & $<\mathbf{0 . 0 0 1}$ \\
\hline \multicolumn{6}{|l|}{ Gender } \\
\hline Boys & 3.6 & 0.9 & 0.8 & 0.8 & 1.2 \\
\hline Girls & 3.7 & 0.9 & 0.8 & 0.9 & 1.2 \\
\hline $\begin{array}{l}\text { Test for difference between genders } \\
(p \text {-value })\end{array}$ & 0.6 & 0.527 & 0.8 & 0.216 & 0.671 \\
\hline \multicolumn{6}{|l|}{ SES (individual) } \\
\hline Low & 3.9 & 1.0 & 0.9 & 0.9 & 1.3 \\
\hline Low-middle & 3.6 & 1.0 & 0.8 & 0.8 & 1.2 \\
\hline Middle & 3.8 & 0.9 & 0.8 & 1.0 & 1.3 \\
\hline Upper-middle & 3.2 & 0.8 & 0.8 & 0.7 & 0.9 \\
\hline High & 2.5 & 0.7 & 0.6 & 0.6 & 0.7 \\
\hline Missing SES & 4.7 & 1.2 & 0.9 & 1.1 & 1.7 \\
\hline Test for a trend by SES ${ }^{c}$ & $<\mathbf{0 . 0 0 1}$ & 0.003 & 0.046 & 0.005 & 0.001 \\
\hline \multicolumn{6}{|l|}{ Grade level } \\
\hline Middle School & 3.6 & 0.9 & 0.8 & 0.9 & 1.2 \\
\hline High School & 3.7 & 1.0 & 0.8 & 0.9 & 1.2 \\
\hline $\begin{array}{l}\text { Test for difference between middle } \\
\text { school and high school ( } p \text {-value) }\end{array}$ & 0.435 & 0.127 & 0.573 & 0.780 & 0.721 \\
\hline
\end{tabular}

${ }^{\text {a }}$ Ethnicities/races with different group letters within column are statistically significantly different at the $p<0.05$ level.

b For intake measure "Other" fast food includes response categories Mexican and fried chicken.

c Test for trend by SES does not include those with missing SES $(n=99)$.

Table 4

Mean weekly frequency of eating at fast-food restaurants by number of fast food restaurants within $1600 \mathrm{~m}$ buffer of respondent HOMES and $800 \mathrm{~m}$ buffer of participant SCHOOLS.

\begin{tabular}{|c|c|c|c|c|c|}
\hline \multirow[t]{2}{*}{ Total number of FF restaurants } & \multirow[t]{2}{*}{ Participant $N(\%)$} & \multicolumn{2}{|c|}{$\begin{array}{l}\text { Unadjusted weekly } \\
\text { frequency }\end{array}$} & \multicolumn{2}{|c|}{$\begin{array}{l}\text { Adjusted }^{\mathrm{a}} \text { weekly } \\
\text { frequency }\end{array}$} \\
\hline & & Boys & Girls & Boys & Girls \\
\hline \multicolumn{6}{|l|}{ Near home ( $1600 \mathrm{~m}$ buffer) } \\
\hline 0 & $241(8.9)$ & 3.2 & 3.6 & 3.3 & 3.7 \\
\hline $1-2$ & $475(17.4)$ & 3.2 & 3.9 & 3.4 & 3.9 \\
\hline $3-4$ & $522(19.2)$ & 3.7 & 3.9 & 3.8 & 3.9 \\
\hline $5-6$ & $553(20.3)$ & 3.2 & 3.3 & 3.3 & 3.9 \\
\hline $7-8$ & $420(15.4)$ & 3.6 & 3.5 & 3.5 & 3.5 \\
\hline $9-10$ & $198(7.3)$ & 4.0 & 3.7 & 3.9 & 3.8 \\
\hline $11+$ & $315(11.6)$ & 4.5 & 4.0 & 4.3 & 3.6 \\
\hline Trend p-value & & 0.007 & 0.873 & 0.059 & 0.632 \\
\hline Higher counts of FF restaurants $p$-value ${ }^{\mathrm{c}}$ & & 0.010 & 0.381 & 0.044 & 0.712 \\
\hline \multicolumn{6}{|l|}{ Near school ( 800 m buffer) } \\
\hline 0 & $1037(38.1)^{\mathrm{d}}$ & 3.7 & 3.8 & 3.6 & 3.6 \\
\hline $1-2$ & $781(28.7)$ & 4.0 & 4.2 & 4.0 & 4.3 \\
\hline $3+$ & $906(33.3)$ & 3.4 & 3.3 & 4.4 & 3.2 \\
\hline Trend p-value $e^{\mathrm{b}}$ & & 0.539 & 0.368 & 0.644 & 0.299 \\
\hline
\end{tabular}

a Fully adjusted including gender, grade level (high vs. middle school), race, and individual SES.

b Trend: whether there is a trend for those living or going to school near more fast food restaurants to eat more.

${ }^{\mathrm{c}}$ Higher counts of fast food restaurants: test of whether those in areas with the highest counts of fast food restaurants (i.e. $11+$ ) within $1600 \mathrm{~m}$ ate more than the average of the rest.

${ }^{\mathrm{d}}$ The number of individuals sampled within schools with different numbers of nearby restaurants is shown. The number of schools in each category $0,1-2$, and $3+$ were 7,6 , and 7 respectively. 
Table 5

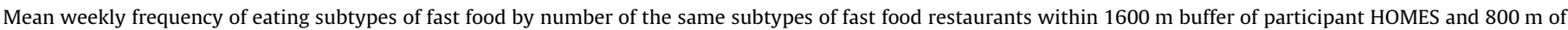
participant SCHOOLS.

\begin{tabular}{|c|c|c|c|c|c|c|c|c|c|c|c|}
\hline \multirow[t]{3}{*}{ Number of fast food restaurants of type } & \multicolumn{5}{|l|}{ HOMES } & \multicolumn{6}{|l|}{ SCHOOLS } \\
\hline & \multirow{2}{*}{$\begin{array}{l}\text { Participants } \\
N(\%)\end{array}$} & \multicolumn{2}{|c|}{$\begin{array}{l}\text { Unadjusted weekly } \\
\text { FF frequency }\end{array}$} & \multicolumn{2}{|c|}{$\begin{array}{l}\text { Adjusted }^{\mathrm{a}} \text { weekly } \\
\text { FF frequency }\end{array}$} & & \multirow[t]{2}{*}{ Participants } & \multicolumn{2}{|c|}{$\begin{array}{l}\text { Unadjusted } \\
\text { weekly FF } \\
\text { frequency }\end{array}$} & \multicolumn{2}{|c|}{$\begin{array}{l}\text { Adjusted }^{\text {a }} \text { weekly } \\
\text { FF frequency }\end{array}$} \\
\hline & & Boys & Girls & Boys & Girls & & & Boys & Girls & Boys & Girls \\
\hline \multicolumn{12}{|l|}{ Traditional burgers and fries } \\
\hline 0 & $867(31.8)$ & 0.9 & 0.9 & 0.9 & 0.9 & 0 & $2193(80.5)$ & 1.0 & 1.0 & 1.0 & 1.0 \\
\hline 1 & $754(27.7)$ & 0.9 & 0.9 & 0.9 & 0.9 & $1+$ & $531(19.5)$ & 0.8 & 1.0 & 0.7 & 0.9 \\
\hline 2 & $625(22.9)$ & 0.9 & 1.0 & 0.9 & 1.0 & & & & & & \\
\hline 3 & $229(8.4)$ & 1.0 & 1.1 & 0.9 & 1.1 & & & & & & \\
\hline 4 or more & $249(9.1)$ & 1.1 & 0.9 & 1.1 & 0.8 & & & & & & \\
\hline Trend $p$-value $\mathrm{e}^{\mathrm{b}}$ & & 0.035 & 0.689 & 0.093 & 0.890 & Dif. $p$-value $\mathrm{c}$ & & 0.258 & 0.926 & 0.066 & 0.673 \\
\hline Higher counts of FF rest. different $p$-value ${ }^{\mathrm{d}}$ & & 0.074 & 0.479 & 0.083 & 0.143 & & & & & & \\
\hline \multicolumn{12}{|l|}{ Pizza } \\
\hline 0 & $568(20.9)$ & 0.8 & 0.9 & 0.8 & 1.0 & 0 & $1504(55.2)$ & 0.9 & 0.9 & 0.9 & 0.9 \\
\hline 1 & $576(21.2)$ & 0.8 & 0.9 & 0.8 & 0.9 & $1+$ & $1220(44.8)$ & 0.9 & 0.9 & 0.9 & 0.9 \\
\hline 2 & $662(24.3)$ & 0.9 & 1.0 & 0.9 & 1.0 & & & & & & \\
\hline 3 & $517(19.0)$ & 0.7 & 0.9 & 0.7 & 0.9 & & & & & & \\
\hline 4 or more & $401(14.7)$ & 1.1 & 0.7 & 1.5 & 0.8 & & & & & & \\
\hline Trend $p$-value $\mathrm{b}^{\mathrm{b}}$ & & 0.015 & 0.140 & 0.012 & 0.202 & Dif. p-value & & 0.953 & 0.844 & 0.998 & 0.822 \\
\hline Higher counts of FF rest. different $p$-value $e^{\mathrm{d}}$ & & $<0.001$ & 0.066 & $<0.001$ & 0.173 & & & & & & \\
\hline \multicolumn{12}{|l|}{ Subs and sandwiches } \\
\hline 0 & $1093(40.1)$ & 0.8 & 0.9 & 0.8 & 0.9 & 0 & $1925(70.7)$ & 0.8 & 0.8 & 0.8 & 0.8 \\
\hline 1 & $1156(42.4)$ & 0.7 & 0.8 & 0.7 & 0.8 & $1+$ & $799(29.3)$ & 0.9 & 0.8 & 0.9 & 0.8 \\
\hline 2 & $267(9.8)$ & 0.8 & 0.7 & 0.8 & 0.7 & & & & & & \\
\hline 3 & $119(4.4)$ & 1.0 & 0.7 & 0.9 & 0.6 & & & & & & \\
\hline 4 or more & $89(3.3)$ & 1.3 & 1.2 & 1.2 & 1.1 & & & & & & \\
\hline Trend p-value & & 0.006 & 0.149 & 0.040 & 0.557 & Dif. p-value & & 0.516 & 0.914 & 0.341 & 0.949 \\
\hline Higher counts of FF rest. different $p$-value $e^{\mathrm{d}}$ & & 0.017 & 0.030 & 0.052 & 0.089 & & & & & & \\
\hline \multicolumn{12}{|l|}{ other $^{\mathbf{e}}$} \\
\hline 0 & $1236(45.4)$ & 1.2 & 1.2 & 1.2 & 1.2 & 0 & $2043(75.0)$ & 1.3 & 1.3 & 1.2 & 1.2 \\
\hline 1 & $632(23.2)$ & 1.1 & 1.3 & 1.1 & 1.4 & $1+$ & $681(25.0)$ & 1.1 & 1.0 & 1.2 & 1.2 \\
\hline 2 & $443(16.3)$ & 1.1 & 1.0 & 1.1 & 1.0 & & & & & & \\
\hline 3 & $160(5.9)$ & 1.1 & 2.0 & 1.1 & 1.9 & & & & & & \\
\hline 4 or more & $253(9.3)$ & 1.6 & 1.1 & 1.5 & 0.9 & & & & & & \\
\hline Trend $p$-value & & 0.028 & 0.222 & 0.172 & 0.867 & Dif. p-value & & 0.503 & 0.269 & 0.832 & 0.927 \\
\hline Higher counts of FF rest. different $p$ - value $e^{\mathrm{d}}$ & & 0.008 & 0.205 & 0.040 & 0.015 & & & & & & \\
\hline
\end{tabular}

a Fully adjusted including gender, grade level (high vs. middle school), race, and individual SES. Adjusting for neighborhood tract income in addition made little difference.

b Trend: whether there is a trend for those living near more fast food restaurants to eat more at $P<0.05 ; t$-test

${ }^{c}$ Because of small numbers of restaurants the comparison for schools was whether there was a difference of consumption between those with 0 and those with 1 or more restaurants at $P<0.05 ; t$-test.

${ }^{\mathrm{d}}$ Higher counts of fast food restaurants: test of whether those in areas with the highest counts of fast food restaurants within $1600 \mathrm{~m}$ ate more.; $t$ - test.

e "Other" fast food intake includes the categories Mexican and fried chicken, while the other category for GIS fast food restaurant counts includes fried chicken and Mexican restaurants but also other types of restaurants such as cookie shops, fried fish restaurants, and Asian take-outs.

more fast food restaurants eat more frequently at fast food restaurants, the answer is only in some circumstances. Specifically, when adolescent males live in environments with very high numbers of fast food restaurants, they eat at fast food restaurants more often and that relationship holds in adjusted analyses. Given that females and males did not differ in neighborhood fast food restaurant access or in overall frequency of eating at fast food restaurants, this may indicate gender specific differential influences on food choices and consumption. Specifically boys living in areas with more exposure and access to fast food restaurants ate more frequently at these venues after adjusting for sociodemographic variables.

In this study we also tested the association between a number of additional socio-demographic variables, beyond gender, and both fast food access (numbers of restaurants) and frequency of eating at fast food restaurants (numbers of meals) for residential and school neighborhoods. In terms of ethnicity/race there were significant differences in both counts of restaurants near homes and frequency of eating at fast food restaurants with the highest intakes among black adolescents. There were also significant associations between SES and frequency of eating at fast food restaurants in the expected, inverse direction. Grade level was significant in terms of numbers of nearby restaurants but not frequency of eating at fast food restaurants. Gender was not significant for either. These findings are especially concerning since diet quality tends to be poorer and obesity rates are generally higher in low-income and minority communities (Larson et al., 2009) and numerous studies have found evidence of racial inequities in access to healthy foods (Kwate, 2008; Fleischhacker et al., 2011; Richardson et al., 2012).

There were no significant associations between access to fast food restaurants around schools and frequency of eating at fast food restaurants. However, it is concerning that there were somewhat more fast food restaurants near schools than near their homes.

These findings extend the work on adolescent food consumption and neighborhood fast food restaurant and convenience store access showing complicated patterns of association. For example 
Davis and Carpenter (2009), using data on 500,000 youth in California, found those with fast food restaurants within $800 \mathrm{~m}$ of their schools consumed more soda and fewer fruits and vegetables than others but were not different in terms of fried potato or juice consumption controlling for sex, age, race, grade, physical activity, and type of urban or rural location. Ding et al. (in press) found an association between fruit and vegetable consumption and home food availability but not the community or neighborhood food environment for children ages 5-18. Powell et al. (2007a), examining $8^{\text {th }}$ and $10^{\text {th }}$ grade students, found higher BMI and overweight was associated with convenience store access at the zip code level though a second paper found that the price of a fast food meal was more important as a determinant of eating and BMI (Powell et al., 2007b). Jago et al. (2007) found that Boy Scouts (mean age $=12.8$ years) who lived closer to fast food restaurants ate more high fat vegetables but also more juice and fruit; those who lived closer to convenience stores ate fewer low-fat vegetables, juice, and fruit. Oreskovic et al. (2009) found that children aged 2 to 18 in low-income towns were more likely to be overweight or obese when there were higher fast food densities but this association was not significant in high-income towns. Crawford et al. (2008), in an Australian study of children aged 8-9 and 13-15, found lower BMIs among children with more fast food restaurants in a $2 \mathrm{~km}$ buffer around their homes. Timperio et al. (2008), also working in Australia, found children aged $10-12$ years ate more fruit and vegetables if they lived further from fast food restaurants, convenience stores, and supermarkets. Studies do find relationships but they are complex.

This research has a number of strengths and limitations. Strengths include examining a large, ethnically and socioeconomically diverse group of adolescents, assessing access to fast food restaurants near both the adolescent's home and school, and examining subtypes of fast food restaurant (spatially and in terms of eating frequency). The robust nature of study results was also improved by providing findings about the relationship between location and consumption for specific types of fast food restaurants.

Another strength is the GIS methods used. It is notoriously difficult to measure fast food restaurants, but the approach of combining key words and chain names used in this study minimizes many of the problems previously identified related to the use of industrial classification codes that had been poorly applied (Forsyth et al., 2010). The study team used buffers to help manage the scale and aggregation components of the modifiable areal unit problem - these are to do with the problem of comparing areas of different sizes and of using data aggregated in arbitrary ways (e.g. postal code boundaries). This study, like many recent studies in the area of food and physical activity environments, attempted to minimize this problem by creating and comparing buffers of consistent sizes and using databases of individual fast food restaurants that were aggregated at these consistent scales (Boone-Heinonen et al., 2010; Owens et al., 2010). This is a static perspective, of course, and developments in wearable global positioning systems will eventually enable researchers to better measure food environments as they are more directly experienced (Rainham et al., 2008). This kind of GPS-based work is, however, still complex and expensive in large studies.

The study does have a number of limitations. It relies on adolescents recalling frequency of fast food restaurant usage and such recall could be faulty. In addition, the study was located in one metropolitan area in a Midwestern state. While there were 2724 participants, representing a diverse population-based sample of adolescents, they attended only 20 different schools also reducing variation in exploring associations between fast food restaurants near schools and adolescents' use of these restaurants. Future research could examine the relationship between fast food access and purchasing fast food meals in different metropolitan areas and in rural locations.

While the study used GIS techniques to measure the environment proximate to major locations, home and school, it did not measure the perceived environment. The perceived environment may be more important than the actual food environment in the decision to consume food. While the study provides useful information for those thinking of intervening by changing the environment (e.g. zoning to limit certain store types) it provides less information for those planning to change behavior through education (changing perceptions).

In general these findings are consistent with earlier studies showing evidence of disparities in fast food restaurant access and complex relations between the food environment and consumption patterns (De Vet et al., 2011). However, this study identified gender differences and some suggestive findings about areas with very high numbers of fast food restaurants indicating a potential threshold effect for fast food exposure. Examining total frequency of eating at fast food restaurants, boys living in the areas with the most fast food restaurants $(11+$ in a 1600 m buffer; about $10 \%$ of the population) ate at fast food restaurants more often. The high levels of eating food from fast food restaurants in areas with a very high density of these restaurants is of public health concern, given the high prevalence of obesity among youth, particularly those from ethnically/racially diverse and low income backgrounds.

Potential reasons for observed gender differences include girls being more concerned about their diet and weight issues, possible gender differences in parental monitoring, the influence of marketing of fast foods directed at males, and likely higher engagement of females in food preparation at home (NeumarkSztainer et al., 2012). Work combining this dataset with earlier samples found that the BMIs of boys but not girls had increased over the period from 1999-2010 (Neumark-Sztainer et al., 2012). Future research could investigate these gender differences and the potential contribution of fast food restaurant use to the observed trends in BMI.

More research is needed to investigate whether there is a specific threshold where adolescent boys living in areas with numbers of restaurants over the threshold consume significantly more fast food meals. This finding may warrant further investigation as a potential issue for policy intervention such as zoning to limit the concentration of fast food restaurants, especially near schools (Ashe et al., 2003; Sturm and Cohen, 2009).

In addition, black, Hispanic, and Native American students lived in areas with significantly more fast food restaurants nearby than white and Asian students. They also ate at fast food restaurants more often, particularly black students. This ethnic disparity in exposure is an important concern. Future work should explore the intersection of race and gender in relation to fast food consumption and neighborhood exposure to fast food restaurants.

\section{References}

An, R., Sturm, R., 2012. School and residential neighborhood food environment and diet among California youth. American Journal of Preventive Medicine 42 (2), 129-135.

Ashe, M., Jerrigan, D., Kline, R., Galaz, R. 2003. Land use planning and the control of alcohol, tobacco, firearms, and fast food restaurants. American Journal of Public Health 93 (9), 1404-1408.

Austin, S.B., Melly, S.J., Sanchez, B.S., Patei, A., Buke, S., Gortmaker, S., 2005 Clustering of fast-food restaurants around schools: a novel application of spatial statistics to the study of food environments. American Journal of Public Health 95, 1575-1581.

Block, J.P., Scribner, R.A., DeSalvo, K.B., 2004. Fast food, race/ethnicity, and income: a geographical analysis. American Journal of Preventive Medicine 27, 211-217. 
Boone-Heinonen, J., Popkin, B., Song, Y., Gordon-Larsen, P., 2010. What neighborhood area captures built environment features related to physical activity? Health and Place 16 (6), 1280-1286.

Boone-Heinonen, J., Gordon-Larsen, P., Kiefe, C.I., Shinkany, J.M., Lewis, C.E. Popkin, B.M., 2011. Fast food restaurants and food stores: longitudingal associations with diet in young adults: the CARDIA study. Archives of Internal Medicine 171 (13), 1162-1170.

Crawford, D., Timperio, A., Salmon, J., Baur, L., Giles-Corti, B., Roberts, R., Jackson, M., Andrianopoulos, N., Ball, K., 2008. Neighborhood fast food outlets and obesity in children and adults: the CLAN study. International Journal of Pediatric Obesity 3, 249-256.

Davis, B., Carpenter, C., 2009. Proximity of fast-food restaurants to schools and adolescent obesity. American Journal of Public Health 99 (3), 505-510.

De Vet, E., de Reidder, D.T.D., de Wit, J.B.F., 2010. Environmental correlates of physical activity and dietary behaviour among young people: a systematic review of reviews. Obesity Reviews 12, e130-e142.

Ding, D., Sallis, J.F., Norman, G.J., Saelens, B.E., Harris, S.K., Kerr, J., Rosenberg, D. Durant, N., Glanz, K., Community food environment, home food environment, and fruit and vegetable intake of children and adolescents. Journal of Nutrition Education and Behavior, http://dx.doi.org/10.1016/j.jneb.2010.07.003, in press.

Esri 2011, 2011. Methodology Statement: Esri ${ }^{\mathbb{R}}$ Data-Business Locations and Business Summary. 〈http://www.esri.com/ /media/Files/Pdfs/library/white papers/pdfs/esri-data-business-locations.pdf $\rangle$.

Fleischhacker, S.E., Evenson, K.R., Rodriguez, D.A., Ammerman, A.S., 2011 A systematic review of food access studies. Obesity Reviews 12, 460-e471.

Forsyth, A., Lytle, L., Van Riper, D., 2010. Finding food: issues and challenges in using GIS to measure food access. Journal of Transport and Land Use 3 (1), 43-65, http://dx.doi.org/10.5198/jtlu.v3i1.105.

Forsyth A. ed., 2012. LEAN GIS (Local Environment for Activity and Nutrition) Protocols (Version 2.1. 〈http://www.designforhealth.net/techassistance/trec >.).

Forsyth, A., Van Riper, D., Larson, D., Wall, N., Neumark-Sztainer, D., M., 2012. Creating a replicable, cross-platform buffering technique: the sausage network buffer for measuring food and physical activity built environments. International Journal of Health Geographics 11, 14 <http://www.ij-healthgeo graphics.com/content/11/1/14

Jago, R., Baranowski, T., Baranowski, J.C., Cullen, K.W., Thompson, D., 2007. Distance to food stores and adolescent male fruit and vegetable consumption: mediation effects. International Journal of Behavioral Nutrition and Physical Activity 4, 35.

Kersten, E., Laraia, B., Kelly, M., Adler, N., Yen, I.H., 2012. Small food stores and availability of nutritious foods: a comparison of database and in-store measures, Northern California, 2009. Preventing Chronic Disease, 9 DOI:http:// dx.doi.org/10.5888/pcd9.120023.

Kwate, N.O., Yau, C.-Y., Loh, J.-M., Williams, D., 2009. Inequality in obesigenic environments: fast food density in New York City. Health and Place $15,364-373$.

Kwate, N.O., 2008. Fried chicken and fresh apples: racial segregation as fundamental cause of fast food density in black neighborhoods. Health and Place 14 (1), 32-44.

Larson, N., Story, M., Nelson, M.C., 2009. Neighborhood environments. Disparities in access to healthy foods in the U.S. American Journal of Preventive Medicine $36,74-81$.

Laska, M.N., Hearst, M., Forsyth, A., Pasch, K., Lytle, L., 2010. Neighborhood food environments: are they associated with adolescent dietary intake, food purchases, and weight status? Public Health Nutrition 13, 1757-1763.
Moore, L.V., Diez Roux, A.V., Nettleton, J.A., Jacobs, D.R., Franco, M., 2009. Fast food consumption, diet quality, and neighborhood exposure to fast food: a multiethnic study of atherosclerosis. American Journal of Epidemiology 170 (1), 29-36.

Neumark-Sztainer, D., Story, M., Hannan, P.J., Croll, J., 2002. Overweight status and eating patterns among adolescents: Where do youth stand in comparison to the Healthy People 2010 Objectives? American Journal of Public Health $92,844-851$.

Neumark-Sztainer, D., Wall, M.M., Larson, N., Story, M., Fulkerson, J.A., Eisenber, M.E., Hannan, P.J., 2012. Secular trends in weight status and weight-rleated attitudes and behaviors in adolescents from 1999-2010. Preventive Medicine $54,77-81$.

Oreskovic, N., Kuhlthau, K., Romm, D., Perrin, J., 2009. Built environment and weight disparities among children in high- and low-income towns. Academic Pediatrics 9, 315-321.

Owens, P.M., Titus-Ernstoff, L., Gibson, L., Beach, M.L., Beauregard, S., Dalton, M., 2010. Smart density: a more accurate methods for measuring rural density for health-related research. International Journal and Health Geographics 9, 8.

Powell, L.M., Auld, M.C., Chaloupka, F.J., O'Malley, P.M., Johnson, L.D., 2007b. Access to fast food and food prices: relationship with fruit and vegetable consumption and overweight among adolescents. Advances in Health Economics and Health Services Research 17, 23-48.

Powell, L.M., Auld, M.C., Chaloupka, F.J., O’Malley, P.M., Johnson, L.D., 2007a. Associations between access to food stores and adolescent body mass index. American Journal of Preventive Medicine 33, S301-S307.

Rainham, D., Krewski, D., McDowell, I., Sawada, M., Liekend, B., 2008. Development of a wearable global positioning system for place and health research. International Journal of Health Geographics 7, 59 <http://www.ij-healthgeo graphics.com/content/7/1/59 $\rangle$.

Richardson, A.S., Boone-Heinonen, J., Popkin, B.M., Gordon-Larsen, P., 2011. Neighborhood fast food restaurants and fast food consumption: a national study. BMC Public Health 11, 543 〈http://www.biomedcentral.com/1471-2458/11/543〉.

Richardson, A.S., Boone-Heinonen, J., Popkin, B.M., Gordon-Larsen, P., 2012. Are neighbourhood food resources distributed inequitably by income and race in the USA? Epidemiological findings across the urban spectrum. BMJ Open 1 (13), 2, http://dx.doi.org/10.1136/bmjopen-2011-000698.

Seliske, L.M., Pickett, W., Boyce, W.F., Janssen, I., 2009. Density and type of food retailers surrounding Canadian schools: variations across socioeconomic status. Health and Place 15, 903-907.

Sherwood, N.E., Wall, M., Neumark-Sztainer, D., Story, M., 2009. Effect of socioeconomic status on weight change patterns in adolescents. Preventing Chronic Disease 6, A19.

Sturm, R., Cohen, D.A., 2009. Zoning for health? The year-old ban on new fast-food restaurants in South LA. Health Affairs (Millwood) 28 (6), 1088-1097.

Timperio, A., Ball, K., Roberts, R., Campbell, K., Andrianopoulous, N., Crawford, D. 2008. Children's fruit and vegetable intake: associations with the neighborhood food environment. Preventive Medicine 46, 331-335.

U.S. Census Bureau, 2009. 2005-2009 ACS 5-Year Estimates. 〈http://www.census. gov/acs/www/data_documentation/2009_release/ $>$.

Wall, M., Larson, N., Forsyth, A., Van Riper, D.C., Graham, D., Story, M., NeumarkSztainer, D., 2012. Patterns of obesogenic neighborhood features and adolescent weight: a comparison of statistical approaches. American Journal of Preventive Medicine 42 (5), e65-e75.

World Health Organization, 2012. Adolescent Health. 〈http://www.who.int/ topics/adolescent_health/en/ $>$.

Zenk, S.N., Powell, L.M., 2008. U.S. secondary schools and food outlets. Health and Place 14, 336-346. 